\title{
OSKAR PFISTER E A CRÍTICA À CONCEPÇÃO FREUDIANA DE RELIGIÃO
}

\author{
Fabiano Veliq
}

\author{
Universidade Federal de Minas Gerais
}

\begin{abstract}
Resumo: A crítica que Freud faz à religião permeia toda a sua obra de forma que podemos afirmar que a questão religiosa se mostra uma grande questão para ele. No entanto, percebe-se que a visão que Freud tem da religião é bastante reducionista e isso fica bastante claro em diversos textos desse autor. Oskar Pfister se coloca como um grande debatedor da questão religiosa no início do movimento psicanalítico evidenciando as diversas lacunas na visão freudiana da Religião. Esse artigo se propõe a mostrar a crítica feita por Pfister à concepção freudiana de Religião visando com isso trazer elementos para o debate entre psicanálise e religião.
\end{abstract}

Palavras-chave: Religião, Psicanálise, Fé, Racionalidade.

\begin{abstract}
The criticism that Freud makes to religion permeates all his work so that we can say that the religious question shown a big issue for him. However, it is clear that the vision that Freud has of religion is rather reductive and it is quite clear in many texts of this author. Oskar Pfister stands as a great debater of the religious question at the beginning of psychoanalytic movement showing the various gaps in Freud's view of religion. This article aims to explain the criticism made by Pfister to Freud's conception of religion in order to bring this element to the debate between psychoanalysis and religion.
\end{abstract}

Keywords: Religion, Psychoanalysis, Faith, Racionality.

\section{Introdução}

É bastante conhecida a forma como Freud procura tratar a questão religiosa vinculada às noções psicanalíticas, mostrando que a Religião estaria apoiada na relação ambivalente entre o pai e o filho derivada do Complexo de Édipo e como a Religião funciona como uma ilusão para que o homem lide com a realidade que o circunda (FREUD, 1913, 1927, 1930, 1939).

Essas explicações de Freud nos mostram uma forma de ver a Religião sob um aspecto nunca antes investigado antes do advento da Psicanálise. $\mathrm{O}$ que Freud nos aponta é que a Religião, por ter sua base em uma dinâmica pulsional, poderia ser substituída pela racionalidade, bastando para isso o empenho do homem em direção à razão. A grande aposta de Freud é a "educação para a realidade" proposta no final de O futuro de uma ilusão, (1927) aposta esta que, como sabemos, não rendeu vitória ao seu apostador. 
A crítica freudiana à Religião tem seus limites, e vários destes limites já foram apontados por diversos autores. É bastante claro o enorme reducionismo presente nos textos de Freud ao tratar da Religião. Uma coisa é mostrar as raízes ambivalentes da Religião a partir da relação pai e filho, mostrar a relação entre o Complexo de Édipo e a criação de uma Religião etc., outra coisa é dizer que a Religião possa ser resumida a apenas essas facetas. Freud, preso ao Iluminismo de sua época, não deu muito espaço em seus textos para pensarmos os aspectos positivos da Religião. Tal apontamento lhe foi feito já no início do movimento psicanalítico pelo seu amigo, pastor suíço, Oskar Pfister ${ }^{1}$.

\section{O início do debate entre Psicanálise e Religião}

Um dos grandes textos para pensar o diálogo entre a fé cristã e a Psicanálise são as cartas trocadas entre Freud e Pfister entre os anos de 1909 e 1939, nas quais os dois amigos debatem, em clima às vezes amistoso, às vezes mais encalorado, temas pertinentes aos dois domínios. Nessas cartas, Pfister tenta mostrar a Freud uma faceta da Religião que o pai da Psicanálise deixou de lado, i.e, a faceta positiva da Religião.

Desde as primeiras cartas entre os dois, a questão da fé já aparece ressaltada. Freud, em uma carta de 18/01/1909², já exalta o fato de as pesquisas psiquiátricas desenvolvidas por ele terem encontrado guarida em uma "cura de almas espiritual"’. Essa aproximação da Psicanálise a outros setores que não o da psiquiatria muito agrada a Freud, que vê aí uma espécie de avanço da Psicanálise a outros meios.

No entanto, Freud sempre via com ressalvas essa aproximação da Psicanálise com outros meios por medo de que isso pudesse comprometer o futuro dessa ciência, por isso uma tentativa sempre muito veemente de definir

\footnotetext{
1 Oskar Pfister nasceu em Wiedikon, subúrbio de Zurique, em 23 de fevereiro de 1873. Seu pai era um pastor de caráter liberal, e sua mãe, uma mulher simples e puritana. Pfister estudou Teologia em Zurique, sob influência de Hegel, Strauss, Schleiermacher, e Teologia Crítica com pensadores como Hermann Kutter e Leonardo Ragaz, introdutores de ideias socialistas no campo da Teologia e Pastoral. Depois de sua formação em Teologia, Pfister obteve o doutorado em filosofia, no qual defendeu uma tese relacionando problemas da Filosofia de sua época à psicologia das religiões a partir da obra do teólogo suiço Bierdermann, que tinha como principal foco aproximar a Religião com a razão. Pfister se envolveu com a Psicanálise a partir do seu contato com Jung, que lhe apresentou a Freud em 1909. Deste primeiro contato, desenvolveu-se uma grande amizade entre Pfister e Freud que perdurou até a morte do último.

2 Todas as citações das cartas entre Freud e Pfister utilizadas nesse artigo tem como referência a obra FREUD, Sigmund. Cartas entre Freud e Pfister (1909-1939): um diálogo entre a Psicanálise e a fé cristã (2009).

${ }^{3} \mathrm{O}$ termo utilizado por Freud é o termo seelsorger, que significa "o religioso que cuida das pessoas de uma igreja e as dirige para Deus" (seele = alma; sorgen = cuidar, prover, preocupar-se por).
} 
o escopo psicanalítico. Segundo Freud, “em termos terapêuticos, só posso invejá-lo quanto à possibilidade de sublimação em direção à Religião. Mas a beleza da Religião certamente não pertence à Psicanálise” (FREUD, 2009, carta de 09/10/1918).

O que Freud sempre faz questão de ressaltar é que a Psicanálise procura evidenciar como a Religião está ancorada em processos infantis, mas ao mesmo tempo mostrar que existem aspectos da Religião que não pertencem ao escopo da Psicanálise. Pfister, no entanto, insiste em afirmar que o trabalho de Freud e o seu trabalho visam a um mesmo objetivo, que é o da cura de almas, mesmo que por caminhos diferentes, e daí não teme em afirmar de Freud que "jamais houve cristão melhor" vive em Deus, e quem luta pela libertação do amor, segundo 1 João 4.16, permanece em Deus" 5 .

\title{
A crítica de Pfister
}

A discussão entre ambos sobre a questão religiosa fica um pouco mais veemente depois do lançamento do livro O futuro de uma ilusão, em 1927. Freud, pouco tempo antes do lançamento do livro, envia uma carta a Pfister afirmando que a obra seria lançada em breve, e que o motivo do adiamento até o presente momento se daria em consideração ao próprio Pfister. Segundo Freud,

\begin{abstract}
Nas próximas semanas sairá uma brochura da minha autoria, que tem muito a ver com o senhor. Eu já a teria escrito há tempo, mas adiei-a em consideração ao senhor, até que a pressão ficou forte demais. Ela trata - fácil de adivinhar da minha posição totalmente contrária à Religião - em todas as formas e diluições, e mesmo que isto não seja novidade para o senhor, eu temia e ainda temo que uma declaração pública lhe seja constrangedora. O senhor me fará saber, então, que medida de compreensão e tolerância ainda consegue ter para com este herege incurável ${ }^{6}$.
\end{abstract}

A resposta de Pfister se dá brevemente e de forma bastante cordial, apenas cinco dias depois.

No tocante à sua brochura contra a Religião, sua rejeição à Religião não me traz nada de novo. Eu a aguardo com alegre interesse. Um adversário de grande capacidade intelectual é mais útil à Religião que mil adeptos inúteis. Enfim, na Música, Filosofia e Religião eu sigo por caminhos diferentes dos do senhor. Não poderia imaginar que uma declaração pública sua me pudesse melindrar; sempre achei que cada um deve dizer sua opinião honesta de modo claro e audível. O senhor sempre foi paciente comigo, e eu não o seria com o seu ateísmo? Certamente o senhor também não vai levar a mal se eu oportunamente

${ }_{4}$ Op. cit. Carta de 29/10/1918.

5 Ibidem.

6 Op. cit. Carta de 16/10/1927. 
expressar com franqueza minha posição divergente. Por enquanto fico na posição de alegre aprendiz ${ }^{7}$.

A postura de Pfister em relação ao texto muito agradou a Freud, que achou bem interessante a proposta de uma resposta pública de Pfister à "declaração de guerra" que Freud havia feito. Segundo Freud,

Da sua magnanimidade eu não esperava outra resposta à minha “declaração de guerra". Alegro-me diretamente pelo seu posicionamento público contra minha brochura; será um refrigério em meio ao coro desafinado de críticas, para o qual estou preparado. Nós sabemos que, por caminhos diferentes, lutamos pelas mesmas coisas para os pobres homenzinhos ${ }^{8}$.

A resposta de Pfister foi publicada em 1928, um ano após o texto de Freud (O futuro de uma ilusão), na revista Imago, volume XIV, caderno 2/3, sob o título $A$ ilusão de um futuro ${ }^{9}$. O texto vem precedido de uma carta a Freud sob o título de "Honrável Professor!", repleta de elogios a Freud. O objetivo do texto, já pelo título, mostra-se de forma bem clara. Nesse texto, Pfister procura responder às críticas freudianas acerca da Religião, mostrando os limites de tal postura.

Já na carta que precede o texto, Pfister deixa clara a sua posição de como compreende a relação entre Psicanálise e Religião. Para ele, a Psicanálise é um magnífico instrumento de purificação da fé e pode contribuir para o amadurecimento e desenvolvimento da Religião. Para Pfister, Freud combate a Religião a partir da própria Religião, pois luta pela verdade, pela libertação e pelo amor. Quem trabalha para aliviar os sofrimentos humanos trabalha em favor do reino de Deus, segundo ele. Conforme Pfister,

Afinal, quem lutou de modo tão gigantesco pela verdade e brigou tão heroicamente pela redenção do amor, este é, quer queria sê-lo ou não, segundo os parâmetros do evangelho, um fiel servo de Deus. E não está longe do reino de Deus quem, pela criação da Psicanálise, elaborou o instrumento pelo qual são serradas as cadeias das almas sofredoras e são abertas as portas do cárcere (2003, p.18).

Há no início da carta uma tentativa de Pfister de mitigar o debate entre Psicanálise e Religião de forma a fazer coincidir os propósitos de ambos os domínios, aproximando-os em nome da libertação dos sofrimentos humanos.

7 Op. cit. Carta de 21/10/1927.

8 Op. cit. Carta de 22/10/1927.

9 O texto de Pfister foi traduzido para o português por Kdarin Hellen Kepler Wondracek e Ditmar Junge e publicado pela Editora Vozes em 2003. As citações do texto de Pfister se referem a essa tradução. 
Pfister finaliza a carta introdutória expressando o desejo de que a Psicanálise e a Religião abandonem a rixa entre elas e que uma sirva para complementar a outra. Segundo Pfister,

Volto-me com toda a determinação contra sua apreciação da Religião [...]. Contudo, faço-o também na esperança de que alguns, que ficaram refratários à Psicanálise com a rejeição da fé religiosa pelo senhor, voltem a contrair amizade com essa ciência, como método e síntese de reconhecimentos empíricos. (PFISTER, 2003, p.19).

A primeira parte do ensaio de Pfister está centrada na crítica freudiana da Religião, principalmente no conceito de ilusão utilizado por Freud. Pfister procurará dar um valor positivo ao conceito de ilusão, mostrando que ela pode coexistir com pensamentos adaptados à realidade. Segundo Pfister, "na ilusão pode estar investido muito raciocínio realista existente” (PFISTER, 2003, p.20). Dessa forma, a relação entre ilusão e realidade se afasta daquela proposta por Freud em $O$ futuro de uma ilusão.

O segundo aspecto abordado por Pfister é a Religião como obsessão neurótica defendida por Freud. Pfister não nega que, em várias manifestações religiosas, haja uma semelhança grande com as neuroses obsessivas, mas isso apenas aconteceria nas primeiras etapas do desenvolvimento religioso, quando a ortodoxia religiosa se faz presente de forma muito forte na vida dos indivíduos. Segundo Pfister, "as obsessões são inconfundíveis em várias religiões primitivas, que ainda não conhecem nenhuma constituição eclesiástica, e também em todas as ortodoxias" (2003, p.21).

Esse caráter opressor não caracteriza a essência da Religião para Pfister, que vê a Religião também de forma evolutiva. À medida que a Religião fosse amadurecendo, ela iria se despojando de seus elementos imaturos. Em uma religiosidade evoluída, o amor supera a culpa. Segundo Pfister, "creio que, pelo contrário, as mais sublimes elaborações religiosas justamente suspendem a obsessão" (2003, p.23).

A figura de Jesus é tomada como exemplo de alguém que supera a neurose coletiva de seu povo e apresenta uma nova proposta religiosa não mais focada na culpa, mas no amor. Segundo Pfister, "Jesus contrapõe seu 'mandamento' do amor ao monismo neurótico obsessivo-compulsivo, que impõe um pesado jugo através das crenças ao pé da letra e do meticuloso cerimonialismo" (2003, p.23). 
A representação paterna em Jesus se torna livre de toda fixação edipiana ${ }^{10}$ por meio de uma proposta que supera todo tipo de heteronomia. Segundo Pfister,

Jesus venceu a neurose coletiva de seu povo introduzindo no centro da vida o amor que, na verdade, é moralmente purificado. Na sua concepção de pai, totalmente purificada das toxinas da ligação edípica, constatamos que foram totalmente vencidos a heteronomia e todo o constrangimento das amarras. $\mathrm{O}$ que se exige das pessoas não é outra coisa senão aquilo que corresponde à sua essência e sua vocação verdadeira, o que favorece o bem comum e - para também dar lugar ao ponto de vista biológico - uma saúde máxima do indivíduo e da coletividade (2003, p. 23s).

Dessa forma, a Lei do amor supera o peso da Lei mosaica e abre espaço para a liberdade, o que leva a uma superação da representação de Deus determinada pelas fixações edipianas. Segundo Pfister, em Jesus "poderíamos provar como sua ideia de Pai é livre de todos os sintomas relativos ao ódio edípico - Deus não deve ser aplacado com sacrifícios, mas amado no irmão" (2003, p.24s).

Pfister deixa claro que o desenvolvimento religioso, e particularmente o judaico-cristão, conduz a um processo de humanização em um combate contra as formas primitivas de representações obsessivas, e lamenta que Freud tenha deixado de lado as mais sublimes expressões da Religião. Para Pfister, o que cria as compulsões e prende as pessoas na neurose é a vida pré-religiosa. $\mathrm{O}$ cristianismo israelita-cristão seria um desenvolvimento da Religião que busca anular a compulsão e criar a libertação, e é exatamente isso que caracteriza a humanização proposta pelo cristianismo.

$\mathrm{Na}$ terceira seção da primeira parte do livro, Pfister procurará trabalhar o problema da Religião como criação imaginária do desejo. Ele deixa claro, já no início dessa parte, que concorda com Freud no ponto de que a Religião é permeada pelo desejo. Segundo Pfister, “eu já sabia havia tempo que as representações de Deus e do além muitas vezes são pintadas com as cores da paleta do desejo" (2003, p.27). Mas isso não seria algo caro apenas à Religião, e sim estaria presente também na própria ciência, assim como o desejo também permearia o próprio ateísmo. O desejo, portanto, circula em todo tipo de criação humana e tenderia a uma evolução que parte de desejos egoístas para aqueles que visam se afastar do seu caráter egocêntrico à medida que o ser humano evolui. Pfister traz novamente o exemplo de Jesus como

10 Pfister aqui está entendendo a figura de Édipo do ponto de vista daquilo que Lacan chamará posteriormente de registro imaginário, ou seja, a partir da ideia de que o filho odeia o pai e deseja a mãe. O pai aparece como um rival para a criança. $O$ registro simbólico do Édipo não aponta nessa direção da rivalidade, mas tem em vista o pai como uma função que trataria mais do ponto de vista da estrutura da constituição do desejo. 
aquele que teria realizado um combate contra o egoísmo mais primário. $\mathrm{Na}$ ideia de reino de Deus proposta por Jesus, haveria a correspondência a uma concepção mais elevada da natureza humana, na qual reinam os ideais éticos universais e, acima de tudo, uma sujeição à vontade divina. Isso, no entanto, não seria uma ausência de desejo como no budismo, nem mesmo uma introversão patogênica. Segundo Morano,

$\mathrm{Na}$ imagem que nos apresenta de seu ideal supremo, isto é, do reino de Deus, os valores religiosos e morais não aparecem como um substituto camuflado e regressivo de desejos sexuais e agressivos insatisfeitos [...], menos ainda como acontece na alucinação, na qual o desejo emerge à margem e em oposição à realidade. Entretanto, ninguém pretenderá que o desejo deva ser proscrito e condenado sempre como algo, por natureza, ilegítimo (2008, p.160).

Pfister deixa claro que desejo e realidade não estão em oposição. Segundo ele, "é possível buscar a satisfação dos desejos de um modo muito condizente com a realidade" (2003, p.29), e isso seria sinal de maturidade pessoal. Novamente, Pfister traz a figura de Jesus como aquele que articula os "imperativos do amor" com os "mandamentos mosaicos", isto é, a demanda interna com a demanda externa. No entanto, segundo Pfister, "o mandamento interno tinha de derrubar o externo" (2003, p.29). Nesse caso, a necessidade moral interna tinha de se originar diretamente de Deus, e como essa necessidade visava ao amor, Deus tinha que se manifestar como amoroso e não mais como o Deus severo do Antigo Testamento. Segundo Morano,

Se Jesus rompe com a imagem do Deus severo e ciumento do Antigo Testamento para evitar todo tipo de religiosidade obsessiva e a substitui pela imagem do Deus-amor, não será tampouco para encontrar aí uma desculpa para uma mera realização de desejos. O dogma cristão - verifica Pfister numa curiosa consideração dele - não pode ser entendido como uma realização de desejos que se tornam realidade, mas como resultado da constatação de uma série de realidades que exigem ser reconhecidas como tais. Tudo parte de uma particularidade propriamente humana, de uma vocação de amor ao próximo, que acaba concluindo pela existência de um absoluto, fonte original do ser, do dever e de todos os valores. O dogma cristão, em suma, não é senão o dogma do amor (2008, p. 161).

No entanto, esse mesmo processo de uma demanda interna não estaria presente na ciência, movendo o seu desenvolvimento? Pfister afirma que vários conceitos tais como "força", "causa", "ação" estariam permeados de certo antropomorfismo. Se realmente fosse assim para toda a ciência, por que a Teologia deveria se constituir como exceção a esta regra? Segundo Pfister,

A história das ciências é uma luta incessante com antropomorfismos e outras projeções não autorizadas de fatos conhecidos sobre desconhecidos. Por que a Religião e a Teologia constituiriam uma exceção? (MORANO, 2008, p. 161). 
A ciência, que seria o juiz imparcial para Freud, também é permeada de diversos antropomorfismos, e isso a torna não tão bom juiz em relação a diversas questões da vida. Ela (a ciência) também estaria repleta de contradições e, por isso, não seria um bom critério para julgar todos os âmbitos da vida, inclusive aqueles que não competem a ela.

Pfister termina essa parte com uma pequena admoestação. Segundo ele,

\begin{abstract}
E não nos esqueçamos: hipóteses científicas podem ser recusadas. Nas questões práticas, de cuja resposta depende a construção da vida, precisamos tomar posição, mesmo quando faltam comprovações irrefutáveis. Do contrário, como se fundaria uma família, se abraçaria uma profissão etc.? Do mesmo modo reside também na Religião uma confiança. Contudo, ai daquele que só se casa por desejo, que escolhe uma profissão e assume uma fé religiosa sem levar em conta cuidadosamente a realidade (2003, p.35).
\end{abstract}

Outro ponto da argumentação de Pfister vai contra a acusação de Freud de que a Religião seria oposta ao pensamento. Pfister afirmará que a Teologia protestante não se encaixa nesse tipo de caracterização que Freud propõe, mas exige um grande pensamento crítico e livre, ou seja, uma "religiosidade adulta". Afirma que os protestantes (nos quais ele se encaixa) criticam a Bíblia e os dogmas com a mesma radicalidade que a Homero e a Aristóteles, de forma que há inúmeros pensadores sérios que não encontraram incompatibilidade entre sua fé e a filosofia ou a ciência. Pfister afirma de si mesmo que "meu próprio pensamento foi ricamente fertilizado pela Religião" (2003, p.37).

A proposta de Freud de uma "educação sem Religião", segundo Pfister, já foi tentada várias vezes em vários círculos comunistas, mas em nada parece ser melhor que uma educação em que o elemento religioso se faça presente.

A Religião tomada como defesa cultural encerra a última seção da primeira parte do livro. Pfister não atribui à Religião uma função de polícia cultural como queria Freud. Segundo ele, "a Religião tem coisas mais importantes a fazer que proteger a mistura de sublimidades e atrocidades que hoje se chama cultura" (2003, p.39). A Religião visa consagrar-se a uma transformação dos seres humanos e a uma sensibilização destes para o fato de que uma determinada civilização se encontra em decadência. Segundo Pfister, "a Religião não deveria tornar-se para nós uma polícia conservadora, mas guia e luz para a verdadeira cultura, retirando-nos da nossa cultura de aparências" (2003, p.40).

A Religião deve ser o fundamento de uma crítica da cultura visando a uma modificação radical da sociedade. Ela exerceria uma função de ideal social 
e não de controle cultural. Pfister nega a ideia de que o céu seria o substituto das frustrações terrenas, e o reino de Deus tampouco seria algo relativo à outra vida. Muito pelo contrário, a Religião se compromete a trazer o reino de Deus para o mundo de forma a humanizar o mundo.

$\mathrm{Na}$ segunda parte do livro, intitulada "O cientificismo de Freud", Pfister critica a concepção de ciência como salvadora do mundo proposta por Freud, acusando-o de uma espécie de "novo messianismo", em que o mais importante seria apenas uma troca de ilusão. Em vez da ilusão religiosa, a ilusão científica. O logos divinizado destrona Deus e governa em seu lugar (PFISTER, 2003, p.43).

Pfister critica o Iluminismo exacerbado freudiano e sua pretensa crença em uma espécie de "experiência pura", que, segundo Pfister, é impossível de existir, pois "não há ciência natural sem metafísica, nunca houve nem haverá" (2003, p.45), e, ao mesmo tempo, demonstra um grande ceticismo em relação aos progressos da ciência como forma de aliviar os sofrimentos humanos ${ }^{11}$.

$\mathrm{Na}$ visão de Pfister, a última frase de $O$ futuro de uma ilusão, "Não, nossa ciência não é uma ilusão. Ilusão seria imaginar que aquilo que a ciência não nos pode dar, podemos conseguir em outro lugar" (FREUD, 1927/1976, p.71), demonstra uma crença de Freud. Todo o texto de Freud, aos olhos de Pfister, procura tratar a ciência como substituta da Religião, e como Pfister não compartilha com Freud esse otimismo com a ciência, fica extremamente difícil para ele ver como possível tal substituição. Pfister valoriza elementos que aparentemente para Freud não são tão relevantes, tais como a música, a arte etc., e isso acaba por fazer com que ele pense que a visão de Freud sobre a Religião se dá de forma bastante reducionista.

Pfister conclui sua obra retomando a ideia fundamental de que a ilusão pode ser muito válida. A questão que se coloca à Religião é o libertar-se de suas configurações neurótico-compulsivas rumo a uma religiosidade adulta, que tem no amor o seu princípio fundamental. A própria Bíblia deverá ser compreendida de outra forma, não mais como uma espécie de "oráculo infalível", mas examinada criticamente (aqui percebemos fortemente o liberalismo teológico de Pfister). A moral não deve ser concebida heteronomicamente, mas fruto da autonomia do indivíduo. O objetivo da

11 Esse tema da relação entre ciência e metafísica foi o centro do debate do Círculo de Viena. As obras de Reichenbach, Carnap, Neurath, todas procuram tratar desse problema, e todo o círculo de Viena se mostra extremamente crítico a toda possível validade do discurso metafísico. A ciência, para o Círculo de Viena, caminharia no sentido oposto a toda metafísica, e pensar em uma "ciência metafísica" seria uma espécie de contradição de termos, pois toda ciência é em última instância experimental. Para uma análise pormenorizada sobre o círculo de Viena, Sobre o tema Cf. QUELBANI, 2009. 
razão não deve ser o de matar o desejo, mas, segundo Pfister, "a verdadeira vida floresce a partir do casamento entre pensar e desejar" (2003, p.55).

Pfister termina seu texto visando a uma espécie de reconciliação com Freud, afirmando que o logos freudiano também impele ao amor humano e à diminuição do sofrimento da mesma forma que a sua proposta também conduz aos mesmos objetivos, só que compreendendo isso como sabedoria e amor divinos. Afirma que "Freud, com sua concepção e obra de vida, está à frente de muitos cristãos frequentadores de igrejas" (PFISTER, 2003, p.56) e que ambos os textos, $O$ futuro de uma ilusão e $A$ ilusão de um futuro, unem-se em torno de uma mesma fé sólida, cujo credo é "A verdade os libertará" (João 8, 32).

\section{Conclusão}

Podemos perceber uma preocupação muito grande de Pfister em de alguma forma conciliar os objetivos da Psicanálise aos objetivos da fé cristã. Esse tipo de vertente será bastante corriqueira no desenvolver do debate entre Religião e Psicanálise e nomes como Erich Fromm (1966) se destacarão nesse tipo de vinculação entre as duas áreas.

Essa tentativa de conciliação de Pfister entre os dois ramos do conhecimento pode gerar algumas incongruências entre as duas áreas. Ao nosso ver, na tentativa de conciliar os dois discursos Pfister acaba por mitigar as diferenças de cunho estruturais na relação entre Psicanálise e Religião. A própria tentativa de Pfister de tornar Freud um "cristão comprometido" por tentar libertar os homens por caminhos diferentes se mostra uma grande tentativa de "salvar Freud" perante os círculos cristãos mostrando como que a Psicanálise poderia ser uma ferramenta para uma purificação da fé.

Freud, por outro lado, nunca reclamou para si nenhum tipo de pertença religiosa e, como foi dito no decorrer desse artigo, sua crítica à religião é bastante incisiva e mesmo que em vários sentidos ela possa ser entendida como reducionista, abre um excelente caminho para o diálogo.

No entanto é bastante visível que há um deslocamento do diálogo entre Psicanálise e Religião para um terreno não propriamente psicanalítico. $\mathrm{O}$ debate se torna muito centrado em torno do conceito de ilusão deixando de lado temas mais caros à doutrina psicanalítica tais como os conceitos de culpabilidade e ambivalência. Pouquíssima atenção é dada a livros como Totem e Tabu (1913) e Moisés e o monoteísmo (1939).

A tentativa conciliatória de Pfister em torno da questão do amor que tem em Jesus o grande paradigma acaba por deixar de lado que a versão psicanalítica do amor é centrada na análise das raízes mais profundas desse sentimento, mais ligado à agressividade, ao ódio e à pulsão de morte. Dessa 
forma podemos notar que faltou a Pfister uma atitude mais crítica que deveria se sobrepor ao seu desejo conciliatório entre as áreas. Tudo isso acaba fazendo com que Pfister fosse obrigado a fazer certa violência aos conceitos psicanalíticos em nome do caráter conciliatório buscado. Ao mesmo tempo a focalização da questão em torno do conceito de ilusão faz tal debate se assemelhar mais a um debate filosófico do que propriamente psicanalíticoreligioso.

Se por um lado houve em Freud demasiado positivismo, em Pfister há um demasiado otimismo na conciliação entre as duas áreas e na aposta de um certo evangelho social fruto de um cristianismo reduzido e de uma psicanálise reduzida.

A crítica de Pfister à concepção de Freud sobre a Religião foi o primeiro trabalho nessa direção e demonstra um diálogo bastante honesto e profícuo que abre um grande caminho para o debate entre Psicanálise e Religião. Permanecem pendentes várias questões abordadas por ambos pensadores e cabe a nós enquanto estudiosos dessas áreas seguir o caminho inaugurado por eles.

\section{Referências}

BÍBLIA SAGRADA. Tradução King James. Disponível em:

<https://www.bibliaonline.com.br/kjv>. Acesso em: 21/05/2015.

FREUD, S. Cartas entre Freud e Pfister. (1909-1939): Um diálogo entre a psicanálise e a fé cristã. São Paulo: Editora Ultimato, 2009

. O futuro de uma ilusão. Rio de Janeiro: Imago, 1976 (Obras Psicológicas Completas de Sigmund Freud).

. Totem e Tabu. Rio de Janeiro: Imago, 2006 (Obras Psicológicas

Completas de Sigmund Freud).

. O mal-estar da civilização. Rio de Janeiro: Imago, 1976 (Obras

Psicológicas Completas de Sigmund Freud).

. Moisés e o Monoteísmo. Rio de Janeiro: Imago, 1976 (Obras Psicológicas

Completas de Sigmund Freud).

FROMM, E. Psicanálise e Religião. Tradução e prefácio de Tracy Doyle. 3 ed. Rio de Janeiro: Livro Ibero-Americano Ltda, 1966.

MORANO, C. D. Psicanálise e Religião: um diálogo interminável. Sigmund Freud e Oskar Pfister. Tradução de Eduardo Dias Gontijo. São Paulo: Loyola, 2008. 
PFISTER, O. “A ilusão de um futuro”. In: WONDRACEK, K. H. K. (org). O futuro e a ilusão. Um embate com Freud sobre Psicanálise e Religião. Petrópolis: Editora Vozes, 2003.

QUELBANI, M. O círculo de Viena. São Paulo: Parábola Editorial, 2009 (Episteme; 3).

E-mail: veliqs@gmail.com

Recebido em: 02/2017

Aprovado em: 09/2017 